\title{
A contribuição positiva de Fichte à formação da filosofia de Schopenhauer
}

Helio Lopes da Silva ${ }^{1}$

1 Professor Titular do DEFIL-IFAC da Universidade Federal de Ouro Preto (UFOP)/MG

E-mail: heliolopes2009@bol.com.br ORCID https://orcid.org/0000-0003-2117-4854

RESUMO: Neste artigo procuro determinar as contribuições positivas que Schopenhauer possa ter recebido do ensinamento de Fichte quando, como um jovem estudante, ele frequentou as aulas e estudou os textos de Fichte nos anos 1811-1813. Vou tentar mostrar que, embora a filosofia de Schopenhauer seja absolutamente original, algumas ideias fichteanas certamente o estimularam na busca de seu pensamento filosófico final.

Palavras-chave: Schopenhauer; Fichte; influência.

ABSTRACT: In this paper I try to determine the positive contritutions that Schopenhauer may have received from Fichte's teaching when, as a young student, he attended the classes and studied the texts of Fichte in the years 1811-1813. I will try to show that, although Schopenhauer's philosophy is absolutely original, some fichtean ideas certainly stimulated him in the pursuit of his final philosophical thought.

Key-words: Schopenhauer; Fichte; influence.

\section{Introdução}

É bem conhecida a maneira como Schopenhauer sempre manifestou uma rejeição completa da filosofia de Fichte, assim como negou que houvesse qualquer influência do pensamento deste seu antigo professor sobre sua filosofia. Num trocadilho espirituoso, Schopenhauer costumava chamar a Doutrina da Ciência (Wissenschaftslehre) de Fichte de "vazio de ciência" (Wissenschaftsleere). Já na primeira edição (1818/1819) de O Mundo como Vontade e Representação, vemos Schopenhauer, baseado na dependência mutua entre sujeito e objeto do conhecimento enquanto partes constitutivas do mundo como representação, criticar o Idealismo de Fichte como loucamente tentando extrair o objeto a partir do sujeito, da mesma maneira como "a teia sai da aranha". Tal idealismo fichteano, diz aí Schopenhauer, só é por ele mencionado como exemplo invertido do mesmo erro cometido pela tentativa, mais "antiga, respeitável e consequente", de extrair o sujeito a partir do objeto feita pelo materialismo (SCHOPENHAUER, (1996) p.6869/(1969) p.32-33). E, no que diz respeito à parte ética da filosofia de Fichte, Schopenhauer diz também que ela só merece ser mencionada por ter, ao amplificar enormemente os erros, intelectualista e formalista, da ética de Kant, tornado mais saliente os pontos fracos desta última (SCHOPENHAUER, 2010, p.188ss). E, assim, ao longo de toda sua obra, Schopenhauer repudia qualquer contribuição que pudesse ter sido fornecida pela filosofia de Fichte, entremeando tal rejeição com ataques ad hominen ao seu antigo professor - pois, conforme nos informa Cartwright, quando atraído a Berlim em 1811 pela fama de Fichte, o jovem Schopenhauer, depois de se esforçar nos cursos "Sobre os fatos da Consciência" e "Sobre a Doutrina da Ciência" de 1811-1812, tomando de memória copiosas apostilas destes cursos, acaba com o tempo desenvolvendo uma grande animosidade e repúdio ao estilo "tortuoso" de seu mestre (CARTWRIGHT, 2010, p.148ss), chegando mesmo em uma destas apostilas, numa anotação característica, a manifestar o desejo de 
encostar uma pistola no peito de Fichte, e fazê-lo confessar, ou que acredita piamente naquele palavreado todo que está proferindo, ou que até então estivera apenas procurando se divertir, ao fazer os alunos de bobos (CARTWRIGHT, 2010, p. 160). Ou seja, tanto filosoficamente, quanto pessoalmente, Schopenhauer sempre se recusou a ver qualquer valor em Fichte.

Porém, alguns estudiosos têm apontado que isto não é bem assim, que a filosofia de Schopenhauer não deixa de, a respeito de pontos importantes, ser devedora do ensinamento de Fichte - por exemplo ${ }^{1}$, e como nos informa novamente Cartwright, já numa das primeiras resenhas de 1819 a O Mundo como Vontade e Representação, Herbart, que, tal como o jovem Schopenhauer, fôra aluno de Fichte, afirma que, além de encontrar-se já em Fichte a ideia de que o ser mais essencial do homem é a vontade, aí encontra-se também aquilo que, na seção 18, Livro II, de O Mundo como Vontade e Representação, aparecerá como a "descoberta" crucial da metafísica de Schopenhauer, a saber, a tese de que os atos da vontade e os movimentos corporais que lhes correspondem, ou satisfazem, são idênticos (CARTWRIGHT, 2010, p. 384). E, mais recentemente, Zöller manifesta, a respeito do mesmíssimo ponto, a mesma opinião (ZÖLLER, 2009, p.41, n.33). Hübscher, editor dos Manuscritos Póstumos de Schopenhauer, aponta que já se encontraria em Fichte a ideia da liberdade enquanto renúncia do mundo (SCHOPENHAUER, 1988, p.xvi). Diante destas semelhanças entre algumas ideias mobilizadas pelas filosofias de Schopenhauer e de Fichte, pareceu a muitos estudiosos que aquela completa desvalorização da filosofia de Fichte por parte de Schopenhauer, aliada aos inúmeros e, em grande parte, imerecidos xingamentos dirigidos por ele a Fichte, foram devidas simplesmente ao empenho com que Schopenhauer procurou afirmar a originalidade de sua obra, e procurou encobrir toda e qualquer possível dívida que esta poderia ter para com os ensinamentos de seu antigo professor.

Mas, se Schopenhauer exagera na desvalorização da filosofia de Fichte, e na recusa de qualquer influência desta sobre seu pensamento, precisamos reconhecer que alguns estudiosos de Fichte talvez estejam exagerando em sentido contrário - por exemplo, em seu Schopenhauer's Fairy Tale about Fichte, Zöller, depois de mencionar os "empréstimos" que Schopenhauer teria tomado de Fichte, tais como as ideias, mencionadas também acima por Herbart, da "identidade vontade-corpo", e da vontade como o ser mais essencial do homem, distingue ainda duas outras doutrinas fichteanas que Schopenhauer teria assimilado. A primeira diz respeito à "intelectualidade da intuição", a saber, ao caráter ativo do sujeito na percepção empírica do mundo externo, sujeito que, ao aplicar o princípio de causalidade ao material crú, passivamente recebido, da sensação, pela primeira vez faz surgir na intuição empírica a percepção de um objeto externo. Segundo Zöller, embora Fichte normalmente caracterize, tal como também o fazem Schelling e Hegel, esta atividade como puramente intelectual, e como referindo-se à natureza incondicionada, absoluta, do Eu, há, no entanto, diz Zöller, uma obra na qual Fichte caracteriza esta atividade de uma maneira mais próxima daquela que virá a ser admitida por Schopenhauer - trata-se, diz Zöller, de A V ocação do Homem, de 1800, onde Fichte discute tal aplicação inconsciente do princípio de causalidade na percepção de objetos. Mas, diante da observação de que não há qualquer indício de que Schopenhauer tenha alguma vez consultado tal obra, Zöller contrapõe que ela foi a obra mais conhecida de Fichte (sugerindo assim que Schopenhauer não poderia ter ficado imune à sua influência), e, diante da observação de que tal obra não consta da bibli-

\footnotetext{
${ }^{1}$ Não pretendemos realizar aqui uma análise suficiente do estado dos comentários a respeito da relação entre as filosofias de Schopenhauer e Fichte encontráveis na literatura filosófica atual. Mencionamos a seguir os nomes de Herbart e Zöller apenas com vistas a obtenção de uma primeira sugestão e aproximação do problema que pretendemos investigar. Especialmente em relação a Herbart, a consideração das características próprias de seu pensamento filosófico ultrapassaria em muito o âmbito da investigação que pretendemos realizar.
} 
oteca deixada por Schopenhauer, que inclui várias outras obras de Fichte, Zöller contrapõe que seria antes preciso “suspeitar de uma deliberada eliminação de vestígios por parte de Schopenhauer" (ZÖLLER, 2012, p.371). Ora, Zöller está aqui retratando Schopenhauer como um plagiador que, deliberadamente, procura apagar os vestígios de seu delito! Como imaginar que alguém tão zeloso de suas economias como Schopenhauer pudesse se desfazer de um livro (teria ele queimado seu exemplar?) apenas para livrar-se da acusação, remota, de plágio? Mas, mais importante, é preciso considerar que a doutrina de Schopenhauer a respeito do caráter ativo da intuição empírica pretende contrapor-se diretamente a "Dedução Transcendental das Categorias" de Kant - numa nota à primeira versão (1781) desta dedução, Kant já afirmava que o objeto da intuição empírica não se dá, como tal, à sensibilidade passiva ou receptiva, mas, sim, é constituído ativamente pela Imaginação a partir deste material fornecido pela sensação (KANT, 1974, p.176, A-121), Imaginação que, no entanto, e embora esta seja uma questão complexa e controvertida nos estudos sobre Kant, é sempre guiada nesta atividade por um conceito ou categoria do Entendimento. E é justamente neste contexto kantiano da dedução das categorias que aquela doutrina de Schopenhauer já aparece na primeira edição (1813) de sua tese doutoral A Quádrupla Raiz do Princípio de Razão Suficiente, onde vemos o jovem Schopenhauer entreter a ideia de uma aplicação, não do conceito, mas sim da intuição da causalidade ao material da sensação - é assim que o jovem Schopenhauer, a respeito desta inferência causal, que põe as modificações do objeto imediato (o corpo próprio) como efeito de uma causa fora dele, constituindo assim o objeto percebido, diz que tal inferência:

(...) não é nenhuma conclusão racional (Vernunfschluss)(..), não temos a ver aqui com o conceito (Begriff) da categoria, mas sim com a categoria mesma (...) ela não é dada através de nenhum conceito abstrato (abstraktenBegriffe), ou algum raciocínio mediado, mas sim é imediata e direta, é uma inferência que eu chamaria de inferência do Entendimento (Verstandesschlusses).(SCHOPENHAUER, 1813, p.55)

Ora, o que separa Schopenhauer decididamente, tanto da interpretação "oficial” da doutrina de Kant, assim como de todos os outros (Fichte, Schelling e, sobretudo Hegel) a este respeito é a afirmação, por parte de Schopenhauer, do caráter exclusivamente intuitivo, isto é, não-conceitual, desta atividade da "Imaginação", ou da "apercepção transcendental", kantiana. E, como o próprio Zöller reconhece, Fichte normalmente concebe tal atividade como "puramente intelectual", isto é, conceitual, e assim não pode ser reconhecido como antecipando o núcleo propriamente original desta doutrina de Schopenhauer.

Em relação à segunda doutrina fichteana que, segundo Zöller, teria sido assimilada por Schopenhauer, a saber, o caráter indefinidamente reiterável do impulso da vontade, constatamos que, embora esta seja, conforme veremos, uma ideia de Fichte que certamente estimulou a elaboração filosófica do jovem Schopenhauer, Zöller, no entanto, toma a seu respeito uma liberdade interpretativa talvez também excessiva. Discutindo o manuscrito do jovem Schopenhauer intitulado "O pesado (ou grosseiro, ou tedioso), conto de fadas de Fichte in nuce", Zöller pretende que Schopenhauer, por "conto de fadas", não estaria afirmando o caráter irreal e inverídico da Doutrina da Ciência de Fichte, mas sim estaria aludindo ao conto de fadas como "gênero literário", já empregado por Göethe e Novalis, que propicia a veiculação de assuntos complexos e difíceis num núcleo (in nuce), tornando-os assim mais acessíveis e manejáveis, tal como, diz Zöller, é o assunto que interessa a Doutrina da Ciência e a Schopenhauer, a saber, as relações entre o supra-sensível e o sensível; e, por "pesado" não se deve, diz Zöller, entender "grosseiro", mas sim algo "em aberto, algo incapaz de chegar ao fim”, de modo que não se está aqui aludindo a uma atividade imperfeita ou precariamente realizada, mas sim “à concepção dos seres humanos como infinitamente se esfor- 
çando, como sempre e em vão buscando o que deve ser querido e feito"(ZÖLLER, 2012, p.374-376). Mas, se isto for assim, como explicar que o jovem Schopenhauer acrescente, em latim, logo após aquele título: “Tenho suportado muitos sofrimentos na cruz!”? (SCHOPENHAUER, 1988, MR2, p. 392). Tendo em vista o conjunto todo das anotações de Schopenhauer às apostilas de aula e aos livros de Fichte, não se vê razão alguma para ultrapassar as significações usuais daquelas expressões, embora isto não exclua, é claro, a possibilidade de que Schopenhauer venha a, depois, numa fase mais madura de sua elaboração filosófica, recuperar ideias de Fichte que, durante estas aulas, eram para ele apenas objeto de zombaria e escárnio.

$\mathrm{Na}$ análise da influência positiva de Fichte sobre a filosofia de Schopenhauer procuraremos, a seguir, evitar ambos os exageros, tanto o exagero dos repúdios manifestos por Schopenhauer em relação a esta influência, quanto o exagero das interpretações que, como a de Zöller acima, parecem fazer de Schopenhauer um mero discípulo, ou até mesmo um mero plagiador, de Fichte. Interessa-nos investigar a maneira como o jovem Schopenhauer, diante das aulas e livros de Fichte, pudesse ter tido contato com ideias que, depois de re-elaboradas por ele, vieram a fazer parte de sua obra original. Por isso, restringiremos nossa análise apenas aos textos de Schopenhauer anteriores à publicação, em 1818/1819, de sua obra prima, O Mundo como Vontade e Representação, já que, a partir daí, na fase madura de sua filosofia, os vestígios "fichteanos" destas ideias desapareceram, na medida em que estas ideias foram harmoniosamente integradas num sistema novo e original.

\section{Schopenhauer, aluno de fichte}

Quando se decidiu a abandonar a medicina em favor da filosofia, o jovem Schopenhauer, depois de frequentar em Göttingen os cursos de Schulze, dirigiu-se, em 1811, a Berlim, em função da fama de que gozava Fichte, cujas aulas, nos diz Cartwright (CARTWRIGHT, 2010, p. 153), eram tremendamente concorridas. O professor Fichte tinha o costume, como nos conta novamente Cartwright (CARTWRIGHT, 2010, p. 157), assim como Hübscher também (SCHOPENHAUER, 1988, MR2, p. xv), de, ao invés de ditar aos alunos a partir de um manual previamente confeccionado, improvisar a cada vez novas versões de sua Doutrina da Ciência, e aconselhava ou exigia que estes não procurassem anotar tudo o que ele dizia, mas sim que, tomando apenas algumas notas indicativas, depois procurassem reconstituir, com seus próprios meios, aquilo que havia sido dito em aula. Foi graças a este procedimento que o jovem Schopenhauer redigiu extensas e apuradas apostilas dos cursos "Sobre os fatos da Consciência" e "Sobre a Doutrina da Ciência”, frequentados por ele entre 1811 e 1812, às vezes acrescentando às margens desta exposição que redige das aulas de Fichte algumas observações suas, o que nos oferece um material particularmente favorável à investigação sobre a recepção da filosofia de Fichte por parte do jovem Schopenhauer.

No curso "Sobre os fatos da consciência", de 1811, Fichte começa dizendo que, tal como toda ciência procura apresentar o fundamento de uma determinada classe de fenômenos, a filosofia, entendida agora propriamente como uma Doutrina da Ciência, tem como fenômeno a ser explicado justamente o conjunto todo do conhecimento (SCHOPENHAUER, 1988, MR2, p. 28). Daí que a Doutrina da Ciência é um conhecimento do conhecimento e, no caso do presente curso, é uma percepção da percepção (SCHOPENHAUER, 1988, MR2, p. 32), percepção esta que se revela sob dois aspectos: como qualidade sensível e como extensão. E, a respeito desta última, Fichte se vangloria de ter descoberto o que ela é - a extensão, diz ele, é a "percepção intuitiva de nossa capacidade infinita de dividir", ou ela é a "visibilidade" desta nossa capacidade (SCHOPENHAUER, 1988, MR2, p. 35). Apesar do jovem Schopenhauer recusar tal defini- 
ção, dado que, segundo ele, a "divisão" já pressupõe a extensão e, portanto, não poderia ser utilizada em sua definição, esta explicação de Fichte alude, no entanto, a um movimento que, conforme veremos na sequência, pode ter deixado algumas marcas no pensamento de Schopenhauer.

Continuando com Fichte, ele na sequência diz que, tal como do ponto de vista da reflexão nós concebemos o Eu como princípio da percepção, do ponto de vista da reprodução (imaginária) nós intuimos o Eu como o princípio da percepção (SCHOPENHAUER, 1988, MR2, p. 50), e esta reprodução, como uma combinação, separação e unificação ideal do múltiplo no espaço, é a contrapartida da ação, que é uma combinação, separação e unificação real do mesmo múltiplo. E depois de uma exposição, difícil, sobre a maneira como, nesta reprodução tornada real que é a ação, surge um conceito-de-fim, Fichte fala da decisão como sendo algo atemporal, como sendo a irrupção da existência supra-factual (ou metafísica) na existência factual (ou física), algo que o jovem Schopenhauer parece aceitar integralmente, e re-elabora da seguinte maneira:

O conceito-de-fim é um conceito que se tornou causal (...). Poder-se-ia dizer que a decisão está fora de todo o tempo, na medida em que ela é um ato da vontade que, como uma coisa-em-si-mesma, está para além de todo o tempo. (SCHOPENHAUER, 1988, MR2, p. 59-60)

Esta talvez seja a primeira menção de Schopenhauer àquela que, segundo ele, seria a sua "descoberta" fundamental, a saber, a de que a coisa-em-si kantiana é, ou pode ser conhecida como, a Vontade. Mas não podemos, no entanto, afirmar que o jovem Schopenhauer, já nesta ocasião, estivesse disposto a resgatar a noção kantiana de coisa-em-si, noção que, em vários outros manuscritos desta época, Schopenhauer recusa como contraditória e impossível (SCHOPENHAUER, 1988, MR1, p. 61 e 104; MR2, p. 270, 290-4). Pode-se dizer que, no momento em que assiste a estas aulas de Fichte, o jovem Schopenhauer ainda está de certo modo imbuído do espírito anti-metafísico, do "fenomenalismo cético"(RAPPAPORT, 1889, p.128) de seu professor anterior, Schulze, assim como das objeções deste à coisa-em-si kantiana. De qualquer forma, a adesão do jovem Schopenhauer a esta ideia de Fichte a respeito da atemporalidade da decisão é tal que, em sua primeira publicação, a primeira edição (1813) de A Quádrupla Raiz. do Princípio de Razão Suficiente, ela é inteiramente reproduzida, embora nenhuma menção seja aí feita ao nome de Fichte, e apontada como o "ponto de contato do incognoscível sujeito do querer (SubjektdesWillens), que está fora do tempo, com o motivo, que está no tempo” (SCHOPENHAUER, 1813, p. 118). Feita, no entanto, em meio a invocação da doutrina kantiana e schellinguiana a respeito do caráter "inteligível" (caráter que, por estar fora do tempo, seria melhor designado, brinca o jovem Schopenhauer, como "caráter ininteligível" (SCHOPENHAUER, 1813, p. 119)), invocação que, aparentemente, tem por função apenas restituir certa necessidade à Lei da Motivação, à conexão entre motivo e ação, tornando-a assim uma figura adicional do Princípio de Razão Suficiente (pois as outras três figuras estabelecem relações já claramente necessárias), tal adesão do jovem Schopenhauer a esta ideia de Fichte não nos permite afirmar que ele já estivesse, nesta ocasião, disposto a conceder à Vontade o status metafísico que ela virá depois a assumir em sua filosofia madura.

Continuando com "Sobre os fatos da consciência", Fichte, depois de apontar para o Eu suprafactual e metafísico como o princípio do Eu factual e físico, diz que este Eu supra-factual é algo que não se torna, mas apenas é, ou existe, ele nunca é não-existente, e depois de, como vimos, apontar para a decisão como um irromper deste Eu supra-factual no domínio factual, diz que tal irrupção pressupõe que, anteriormente, aquela existência determinante do Eu supra-sensível houvera sido obstruída, algo que se revela 
na consciência como o sentimento de um impulso, um empenho em ser princípio: este impulso, diz Fichte, é a expressão imediata da existência supra-factual, existência na qual nada surge, tal como ela mesma não se tornou, e, portanto, nada surge nem mesmo no impulso, que é sem variação e sem mudança. Assim, diz Fichte:

Em relação ao todo do tempo o impulso é eterno, mas agora estamos falando de sua satisfação. Entretanto, não podemos falar de sua abolição, pois o impulso dura para sempre (...). Como isto pode ser conciliado? O impulso só é satisfeito no que diz respeito à forma, ao conceito-de-fim - a ação, que se conforma a este conceito, muda o mundo, assim como muda a visão de mundo, mas o impulso precisa, portanto, aparecer de novo com novas demandas. (SCHOPENHAUER, 1988, MR2, p. 63) itálicos nossos.

Ora, Fichte parece estar aqui se referindo à característica teleológica ou finalística do impulso como dizendo respeito apenas à forma, e à satisfação deste impulso como não afetando ou diminuindo a eternidade e atemporalidade deste. Tal como veremos ocorrer também no Sistema da Eticidade, onde Fichte propõe e procura resolver esta mesmíssima questão, é como se os "conceitos-de-fim" fossem uma vestimenta necessária, mas provisória, do impulso eterno. É assim que, numa longa anotação, o jovem Schopenhauer procura denunciar esta nova versão do "conto de fadas" de Fichte, versão que, embora diferente daquela considerada por Zöller acima, possui, no entanto, o mesmo conteúdo, ou núcleo: segundo Schopenhauer, Fichte estaria querendo colocar uma alma, um Eu, que é uno, imutável e auto-suficiente, como fundamento de um mundo que é completamente múltiplo, mutável, estranho e desconcertante. Mas,

Para explicar isto, ele (Fichte) dá à alma um impulso que é igualmente estranho e desconcertante, um impulso que sempre quer alguma coisa e, quando a obtém, quer novamente alguma outra coisa; e assim ele coloca o mundo em movimento. (SCHOPENHAUER, 1988, MR2, p. 64) itálicos nossos.

É curioso que o jovem Schopenhauer qualifique como “estranha e desconcertante" esta característica do impulso, tal como descrita por Fichte, já que ela se assemelha à conhecida insaciabilidade da Vontade, tal como será posteriormente formulada por ele em sua filosofia madura, isto é, ao fato da Vontade, quer não obtenha, quer obtenha o que quer, continuar querendo. E, conforme vimos anteriormente em conexão com a versão do mesmo "conto de fadas" considerada por Zöller, trata-se aqui do caráter indefinidamente, infinitamente, reiterável do impulso atemporal. É claro que, no âmbito geral do pensamento de Fichte, trata-se aqui daquela maneira como a atividade prática do Eu, embora se aproxime reiterada e indefinidamente de seu ideal (a assimilação do não-Eu ao Eu), nunca chega a realiza-lo completamente, de modo que esta atividade de assimilação permanece sempre como uma tarefa a ser realizada, permanece sempre como um Dever. Mas, transferida ao impulso (que Fichte neste curso ainda não qualifica claramente como "vontade", o que será feito, no entanto, em seu Sistema da Eticidade, que consideraremos em breve), esta característica insaciável do impulso, tal como descrita por Fichte, não pode, em que pese a zombaria e escárnio que o jovem Schopenhauer lhe dirige, ter deixado de marcar o seu pensamento filosófico.

Mas um outro tema, presente nestas apostilas das aulas de Fichte, pode também ter deixado marcas na elaboração filosófica do jovem Schopenhauer - após explicar como aquela alteração do mundo provocada pela ação com finalidade constituirá um novo mundo da percepção intuitiva, que será a base de um novo conceito-de-fim, e assim, indefinidamente, Fichte diz que:

O mundo dado 'A' é imutável e parado; o que se desenvolve é o Eu, e a lei fundamental deste desenvolvimento é o impulso que, em infindáveis conceitos-de-fim e ações, torna-se intuitivamente percep- 
tível ao infinito. Qual é a finalidade do mundo que foi dado no início? Tornar o impulso intuitivamente perceptivel. O mundo, tal como era de início, uma atividade imaginada não ser um princípio, é a perceptibilidade intuitiva do impulso como algo sem fim (...). (SCHOPENHAUER, 1988, MR2, p. 70) itálicos nossos

Tal como, antes, a extensão foi dita ser a visibilidade de nossa capacidade de dividir indefinidamente, agora o mundo é dito ser a visibilidade, a perceptibilidade do impulso enquanto desprovido de fim. A partir da elaboração de Fichte até aqui, seria importante frisar que "fim", acima, significa término, e não finalidade - pois, em momento algum Fichte parece, neste curso, admitir que uma ação possa ocorrer sem que a reprodução acerte (ela precisa, diz Fichte, arriscar) o conceito-de-fim que seja adequado ao impulso, impulso este que, antes e sem isso, permanecerá insatisfeito como um sentimento sem-forma (SCHOPENHAUER, 1988, MR2, p. 62). Veremos, em breve, que será justamente esta imbricação íntima entre o impulso da vontade e o conceito-de-fim, admitida por Fichte, que será negada por Schopenhauer. Mas, de qualquer forma, Fichte parece, acima, a um passo de dizer, como dirá posteriormente a filosofia madura de Schopenhauer, que o mundo é a visibilidade, ou a perceptibilidade intuitiva, do impulso, ou da vontade. É bem verdade, porém, que, em Fichte, tal "visibilidade" é concebida no quadro teórico do esquematismo, que talvez se afasta um bocado do esquematismo kantiano, e que Fichte exemplifica, neste curso, assim - o ser da substância, o suporte da extensão e das qualidades sensíveis, aparece na percepção comum como um ser fora de nós. Mas tal ser, diz Fichte, na realidade corresponde a uma auto-intuição do conhecimento:

Mas, por que ele não nos aparece como conhecimento, e sim como um ser fora de nós? Porque toda imagem só é possível através de seu oposto, através de algo que não é imagem, e em relação ao qual aquela imagem é imagem. Nós pomos, portanto, na percepção comum um ser (einSein) independemente de nosso esquematizar. (SCHOPENHAUER, 1988, MR2, p. 40-41)

Assim, para Fichte, toda a realidade da extensão, do mundo e do ser da substância exterior a nós seria algo simplesmente posto em função de nosso esquematismo - é como se ele dissesse que o principal e primeiro é a Imagem (a auto-intuição do conhecimento), e apenas em consequência desta imagem precisar ser imagem, precisar ser imagem de alguma coisa, é que então esta "alguma coisa"(o mundo, a extensão, o ser da substância) é posta, "alguma coisa” esta que não é imagem, que não é imagem de nada, e em relação a qual aquela primeira imagem é imagem. Trata-se de uma inversão da concepção comum e vulgar, segundo a qual existem, primeiro, as coisas fora de nós, que não são imagens de nada, e apenas posteriormente, uma vez dadas estas coisas, é que podemos fazer imagens ou cópias destas coisas, em particular, fazer imagens destas coisas em nossa imaginação, em nossa representação, enfim, em nosso conhecimento. Fichte pretende, evidentemente, inverter esta prioridade, pretende colocar a imagem (o conhecimento) como fundamento da coisa figurada ou conhecida por ela. Mas, embora Schopenhauer nunca tenha, tanto em sua filosofia madura, quanto nesta fase juvenil de sua elaboração filosófica, dedicado qualquer atenção especial à faculdade da Imaginação e ao tema do "esquematismo", seja kantiano, seja fichteano, parece bastante razoável admitir que esta elaboração de Fichte a respeito do mundo como "perceptibilidade", ou como "visibilidade" do impulso deve ter deixado marcas no espírito do jovem Schopenhauer.

Mas vejamos mais um, e último, desenvolvimento destas aulas de Fichte que pode ter sugerido ao jovem Schopenhauer algumas ideias - aquele impulso, continua Fichte, é o princípio básico da percepção intuitiva factual, mas o conhecimento pode desprender-se ou liberar-se deste impulso, e então o todo da percepção intuitiva se torna vazio, e vazio em relação àquilo que é "mais alto" - tal transição, diz Fichte, é 
a liberdade, que consiste simplesmente neste "desprender-se formal do impulso, neste ato puro sem qualquer qualidade” (SCHOPENHAUER, 1988, MR2, p. 79). Nesta percepção intuitiva "mais alta”, o conhecimento se desprende de todas as determinações (multiplicidade, espaço e tempo, etc.) que constituem a base da percepção intuitiva factual, de modo que nesta percepção mais alta tudo o que for múltiplo, todas as formas-conceituais, já não ocorrem, e, diz Fichte, "O que ela (a percepção intuitiva mais alta) é em sua essência real, isto nós já sabemos há muito tempo. Ela é a forma original do Ser”, ao que o jovem Schopenhauer aplaude: "Verdadeiramente dito!"(SCHOPENHAUER, 1988, MR2, p. 80). Daí, finaliza Fichte, podemos ver como o mundo não é um nada abandonado ao acaso, mas sim que ele é arranjado como a “expressão possível do moral, e é assim santificado”.(SCHOPENHAUER, 1988, MR2, p. 84).

Segala e de Cian lembram que esta intuição "mais alta" de Fichte se assemelha à noção, entretida pelo jovem Schopenhauer nesta época, de "consciência melhor", que consiste também neste desprender-se das determinações, principalmente as determinações temporais, da consciência empírica (SEGALLA e DE CIAN, 2002, p.06). Daí o aplauso que ele manifesta, não só em relação a esta noção de Fichte, mas também às noções semelhantes de Schelling a respeito de sua "intuição intelectual" (SCHOPENHAUER, 1988, MR2, p. 347), e de Espinosa a respeito de seu conhecimento intuitivo de "terceiro gênero" (SCHOPENHAUER, 1988, MR1, p. 360). Mas, de qualquer forma, podemos notar que, embora Schopenhauer procure, na fase madura de sua filosofia, ridicularizar toda esta tentativa de Fichte de fazer o mundo sair do Eu, como a "teia sai da aranha", quando se atenta para os aspectos do Eu que Fichte mobiliza nesta tentativa - um impulso atemporal, que é manifestação imediata do ser supra-sensível, impulso em relação ao qual o mundo é apenas a perceptibilidade ou visibilidade, impulso em relação ao qual os conceitos-defim são como que vestimentas provisórias, impulso que, quer não seja satisfeito, quer seja, não cessa, impulso do qual se desprende e se livra uma forma de conhecimento intuitivo mais alto, desprendimento este que constitui a liberdade, e através do qual o todo da intuição empírica é esvaziado, ocasião então em que se vê que o mundo é expressão do moral, etc. - vemos tratar-se de temas que, inequivocamente, não poderiam ter deixado de impressionar o jovem Schopenhauer, e que possivelmente constituirão o quadro teórico geral a partir do qual Schopenhauer proporá sua inovação. Veremos, porém, que é em conexão com a leitura do Sistema da Ética de Fichte que o jovem Schopenhauer encontrou meios de, mesmo estimulado por tais temas fichteanos, re-elaborá-los, indo assim além daquilo que Fichte explicitamente admitia.

\section{Schopenhauer e o Sistema da Ética de Fichte}

Além das aulas, o jovem Schopenhauer procurou nos livros publicados por Fichte um maior esclarecimento sobre sua doutrina, e a leitura do Sistema da Ética de Fichte, realizada em 1812, tem sido apontada por alguns comentadores (Herbart, Zöller) como sendo a que mais influenciou Schopenhauer. São três os temas schopenhauerianos que estes autores assinalam como já presentes nesta obra de Fichte: 1) a identidade vontade-corpo. 2) a vontade como o ser mais essencial do homem e 3) a liberdade como negação da vontade.

\section{1) A identidade vontade-corpo:}

Fichte inicia o Sistema da Ética dizendo que, tal como a filosofia teórica procura indicar as condições sob as quais as nossas representações subjetivas se adequam a um Ser objetivo, a filosofia prática procura mostrar as condições sob as quais um Ser objetivo se adequa às nossas representações subjetivas, em particular, se adequam aos nossos conceitos-de-fim (Zweckbegriff), ou seja, trata-se das condições sob as quais o Eu pôe-se como Eu ativo, ou atuante (FICHTE, 2005, p.08). Como, nesta última relação, o ser ou 
o objeto sobre o qual atua o Eu é algo objetivo, então, diz Fichte, apenas através daquilo que é objetivo no Eu é que esta atuação ou ação torna-se possível. Mas, pergunta Fichte, o que significa, e como é possível, algo objetivo seguir-se a um conceito?

Isto só pode significar que o conceito mesmo aparece para mim como algo objetivo. Mas o conceito-defim, visto objetivamente, é chamado de ato de querer (einWollen), e a representação de uma vontade (einesWillens) não é nada mais do que este aspecto necessário do conceito-de-fim (...). (FICHTE, 2005, p.16)

Como o material sobre o qual o Eu atua é algo objetivo, e como é impossível para este material ser afetado por outra coisa que não seja algo igualmente material, então, diz Fichte, o Eu precisa tornar-se para si mesmo algo material, o corpo material. E, como a vontade é suposta exercer causalidade sobre este corpo,

A vontade é, portanto, também diferente do corpo, e ela aparece como não sendo o mesmo que o corpo. Esta distinção, entretanto, não é nada mais do que uma outra separação entre o subjetivo e o objetivo, ou, mais especificamente, é um aspecto particular da separação original. Nesta relação a vontade é o que é subjetivo, e o corpo o que é objetivo (FICHTE, 2005, p.16)

Ora, Fichte fala aqui como se a vontade fosse, em relação ao conceito-de-fim, o aspecto objetivo, e, em relação ao corpo material, o aspecto subjetivo. Foi, certamente, apenas em conexão com esta última relação, a da vontade como o aspecto subjetivo daquilo que, sob o outro aspecto, sob o aspecto objetivo, se apresenta como corpo material, que aqueles comentadores (Herbart, Zöller) entenderam já ter sido por Fichte formulada a tese de Schopenhauer sobre a identidade entre as impulsões da vontade e os movimentos corporais. Acontece, porém, que estes comentadores não levaram em conta a primeira relação, aquela em que a vontade aparece, necessariamente, como o aspecto objetivo daquilo que, sob o outro aspecto, sob o aspecto subjetivo, aparece como o conceito-de-fim. A vontade, que Schopenhauer verá como o aspecto "subjetivo" dos movimentos objetivos do corpo material, não é, com efeito, esta vontade que Fichte diz ser necessariamente o aspecto "objetivo" do conceito-de-fim subjetivo. Com efeito, e conforme veremos, será justamente em conexão com as elaborações de Fichte a respeito das relações entre, de um lado, o impulso ou a vontade, e, de outro lado, o conceito-de-fim, que encontraremos, tanto a maior contribuição de Fichte ao pensamento de Schopenhauer, como o ponto em que este começa por afirmar sua originalidade própria. Por enquanto, podemos notar que, para Fichte, o conceito-de-fim tem uma prioridade tal que, na sequência da passagem acima, ele diz que, da mesma maneira como as propriedades mutáveis da matéria são a mesma matéria imutável, apenas vista sob um aspecto diferente, assim também "a causalidade do conceito com respeito àquilo que é objetivo aparece, respectivamente, como vontade e como corpo quando vistos sob aspectos diferentes". (FICHTE, 2005, p.17). Ou seja, vontade e corpo são apenas dois aspectos da mesma causalidade do conceito-de-fim com respeito ao objeto.

\section{2) A vontade como o ser essencial do homem.}

Logo a seguir Fichte, após enunciar o postulado "Eu me encontro a mim mesmo apenas como querente ${ }^{2 \prime}$, diz que, ao querer, acrescentamos pelo pensamento a ideia de algo subsistente, de algo que é suposto ser o Sujeito do Querer (das Wollende), que está engajado neste querer, e ao qual o querer e a ${ }^{2}$ Apesar de estranha, e talvez inexistente em português, a expressão que empregamos aqui, “querente”, foi necessá-
ria, já que a expressão "desejante" talvez não fosse capaz de exprimir exatamente o que se pretende. 
vontade são inerentes, e que é suposto estar presente independentemente da consciência que dele tenho. Daí, continua Fichte, que, da substância do Eu, ou do Eu substancial, temos imediatamente duas manifestações: o pensar, e o querer. Mas, originalmente, o pensar não constitui um objeto especial da consciência, já que ele coincide e é esta consciência mesma:

Apenas na medida em que a consciência se dirige a algo de outro, a algo objetivo, e é posta em oposição a este algo, torna-se ela mesma objetiva neste ato de contrapor-se (FICHTE, 2005, p. 26).

A consciência (o pensar), que é algo subjetivo, só se torna objetivo para si mesmo quando contraposto a algo outro, algo diferente do pensar, a algo objetivo. E já vimos que o querer é o aspecto objetivo do conceito-de-fim subjetivo. Assim, o querer, e não o pensar, é a manifestação objetiva da substância do Eu, de modo que, finaliza Fichte, apenas na medida em que sou consciente do querer, sou consciente de mim mesmo. O jovem Schopenhauer parece concordar com esta ideia de Fichte de que o Eu só se conhece como querente, e não como pensante (SCHOPENHAUER, 1988, MR2, p. 400), e isso a ponto de introduzir em sua primeira publicação, A Quádrupla Raiz do princípio de RaðãoSuficiente de 1813, e tal como ocorrera acima com a ideia de Fichte a respeito da "decisão atemporal", a mesma distinção entre o sujeito conhecedor (SubjektdesErkennens) e o sujeito querente (Subjektdes Wollens), acrescentando, porém, que a identidade entre ambos numa mesma palavra, "Eu", é o "milagre incompreensivel por excelência" (SCHOPENHAUER, 1813, p. 112-113). Foi, com certeza, em conexão com esta passagem do Sistema da Ética que alguns comentadores entenderam que já havia sido antecipado por Fichte a ideia de que o ser essencial do homem é o querer, ou a vontade, e de que, neste, o querer teria prioridade sobre o pensar. Porém, o teor geral da elaboração a seguir de Fichte mostra que, de modo algum, haveria nele tal prioridade do querer sobre o pensar - pois Fichte diz, na sequência, que, quando pensado como um objeto, e o Eu só pode ser objeto enquanto Sujeito do Querer, o Eu aparece essencialmente a si mesmo como uma tendência em direção à auto-atividade, e isto em função da auto-atividade mesma. Ele aparece como a "tendência absoluta em direção ao absoluto", como a indeterminabilidade absoluta através do que quer que seja fora dele mesmo, ou como "a tendência em determinar-se absolutamente, sem qualquer ímpeto externo" (FICHTE, 2005, p. 33). Não se trata, diz Fichte, de uma mera força (Kraft), ou poder (Vermögen), nem de um impulso (Trieb), pois estes operam necessariamente e de uma maneira materialmente determinada, ao passo que, e conforme mostra o interessante exemplo da "mola metálica" (FICHTE, 2005, p. 32ss), um ser só pode ser tido como livre, isto é, como auto-determinado, quando ele, de certa forma, pre-existe à sua natureza, e seja antecedente ao conjunto de suas determinações. A mola metálica não pode ser pensada como livre justamente porque, no pensar a mola, imediatamente pensa-se na sua natureza de coisa, numa subsistência fixa, desprovida de qualquer movimento interno, passiva e morta. Se quisermos, por outro lado, pensar um ser livre ou auto-determinado, precisamos pensar num:

(...) ser cujo fundamento não esteja num outro ser, mas em algo de outro. Outro que o ser, entretanto, não há para nós nada a não ser o pensar. Portanto, aquele ser que você é capaz de pensar como um produto da liberdade teria que ser um ser que provém do pensamento (...). O pensamento não é de modo algum posto como algo subsistente, mas sim como agilidade (Agilität), e puramente como agilidade do intelecto. De modo a que alguma coisa seja pensada como livre, você exigia que ela se determinasse a si mesma, e não fosse determinada a partir de fora, e nem por sua própria naturęa. O que significa este 'a si mesma’? Alguma dualidade está, obviamente, sendo pensada neste caso. O que é livre é suposto ser antes de ser determinado; é suposto ter uma existência (Dasein) independente de sua determinação (...). Isto só pode ser pensado (sob a pressuposição de que) como um intelecto que tem um conceito de seu 
próprio ser real, o que é livre precede seu ser real, e este intelecto contém o fundamento deste último (...). Nossa tese, portanto, é que apenas um intelecto pode ser pensado como livre (...), pois apenas mediante isto ele subsume seu próprio ser a algo mais alto do que qualquer ser, isto é, subsume-o ao conceito (...).”(FICHTE, 2005, p.38-41)

Fica claro, assim, que, para Fichte, aquele impulso e aquele querer, que era uma mera tendência à auto-atividade, uma mera tendência à auto-determinação, só deixa de ser tendência, só chega efetivamente à auto-atividade e à auto-determinação quando, submetida à tutela do intelecto e do conceito (BotmässigheitdesBegriffs), tranforma-se na "força absolutamente real do conceito" (absolutereelle Kraft desBegriffs) (FICHTE, 2005, p. 37), e só então trata-se efetivamente de um ser auto-determinado, de um ser livre, e, enfim, de um ser dotado de vontade (FICHTE, 2005, p. 37). Pois, para Fichte, "vontade" e "vontade livre" são sinônimos (FICHTE, 2005, p. 150). Assim, parece-nos que Fichte de modo algum estaria afirmando, como sugerem aqueles comentadores, uma prioridade do querer e de uma vontade nãoconceptual sobre o pensar do intelecto através de conceitos. E a passagem acima também deixa claro que, para Fichte, a vontade livre, que é a vontade como tal, nada mais é do que um aspecto sob o qual um intelecto se determina através de seus conceitos, em especial, do conceito-de-fim.

Assim, embora seja muito provável que a afirmação de Fichte, no sentido de que "o sujeito só se conhece como sujeito da vontade (e não como sujeito do conhecimento)" tenha influenciado Schopenhauer, colocando-o na pista de um "Sujeito do querer" que logo se transforma, depois de sua tese doutoral de 1813, num "objeto imediato" que é o "corpo (material) próprio", e que é "vontade objetivada, ou tornada objeto”, a outra implicação, destacada por aqueles autores (Herbart, Zöller), desta ideia, a saber, a afirmação de que o querer no homem teria preponderância sobre o pensar, esta ideia schopenhaueriana não pode, no entanto, e como acabamos de ver, ser atribuída a Fichte.

Algumas anotações do jovem Schopenhauer nesta obra de Fichte apontam, porém, na direção dos futuros desenvolvimentos que ele dará a sua elaboração filosófica - por exemplo, quando Fichte diz que, ao passar para o tutela do intelecto e de seus conceitos, aquele impulso, aquela tendência à auto-atividade, perde toda referência ao meramente subsistente e ser-posto, transformando-se em pura atividade, sem qualquer impulso, tendência, inclinação, por mais sutis que estas possam ser pensadas, sendo, esta força ativa do conceito, apenas uma faculdade ou capacidade (FICHTE, 2005, p.42), o jovem Schopenhauer anota:

Se divido o Eu em algo que conhece e em algo que quer, eu, tão logo os separe, constituo, por este mesmo ato, um querer sem objeto, Objekt (pois este é ocupação exclusiva do conhecer), e um conhecer sem impulso, Trieb (pois este é o querer). Agora, como o querer, de modo a se expressar (sichäussern), precisa de um objeto, ele cai então sob o domínio do conhecer, que lhe dá o objeto. Como eu disse, o conhecer é sem impulso.

Mas, então, de onde ultimamente provém a determinação daquilo que é conhecido, e daquilo que é querido?" (SCHOPENHAUER, 1988, MR2, p. 401/(1864),HN, p. 179)

O jovem Schopenhauer parece, aqui, e em conexão com a distinção fichteana entre um sujeito do conhecer e um sujeito do querer, entreter a ideia de um querer sem objeto, o que, no caso, significa um querer sem fim ou finalidade. E o conhecer é dito desprovido de impulso, algo que, parece, contradiz a alusão, acima, de Fichte à "força absolutamente real do conceito". Mas não podemos, é claro, extrair destas hesitantes anotações do jovem Schopenhauer mais do que elas contêm. De qualquer forma, é curioso notar que, um pouco depois (1814), quando já começa a formular sua concepção original, o jovem Schopenhau- 
er, após dizer que "o mundo como coisa-em-si" é uma grande vontade que não sabe o que quer, e que "o mundo como fenômeno" é o conhecimento que esta vontade adquire a respeito do que ela quer, e que aí se revela o "milagre" da identidade entre os sujeitos do querer e do conhecer, se pergunta:

Mas, pode a vontade chegar a conhecer? Pode avontade fazer outra coisa que não querer? Por outro lado, pode o conhecimento guiar e dirigir avontade, vontade que é a única coisa que dirige? (SCHOPENHAUER, 1988, MR1, p.185)

É claro, então, que, tal como indicado por aqueles autores (Herbart, Zöller), a leitura, realizada pelo jovem Schopenhauer, desta obra de Fichte forneceu-lhe um ímpeto e estimulo decisivo ao desenvolvimento de sua filosofia, mas não se pode dizer que Schopenhauer tenha apenas prolongado e ampliado noções de Fichte já presentes nesta obra - pois, nela, Fichte está longe de admitir, seja esta vontade ou querer desprovido de finalidade, desvinculado de qualquer conceito-de-fim, seja este conhecer conceitual desprovido de impulso e de força própria.

Voltando ao Sistema da Ética, Fichte diz que aquele impulso ou tendência à auto-atividade e à autodeterminação, que, tal como ocorria no caso da mola metálica, resultará necessariamente numa ação tão logo condições externas sejam dadas (FICHTE, 2005, p. 44), ao passar para a tutela dos conceitos, deixa de atuar com necessidade e mediante compulsão mecânica, já que “o conceito não é determinável por meio do impulso, mas apenas através de si mesmo” (FICHTE, 2005, p. 46). E é assim que Fichte resume o resultado de sua dedução:

Um ser racional, considerado como tal, é absoluto e auto-suficiente (...). Um ser racional é, ele mesmo, suposto produzir tudo o que ele alguma vez chegar efetivamente a ser. Você precisa, portanto, atribuir a tal ser algum tipo de existência (Existenz) anterior a todo ser e subsistência efetiva (objetiva) (...). Este modo de existir não pode ser outro que não o existir como um intelecto em e com conceitos (...). Sobretudo, você precisa atribuir a este intelecto o poder de produzir (hervorbringen) um ser através de seu mero conceito (...). Numa palavra, em seu conceito de um ser racional você precisa ter pensado aquilo que derivamos (...) sob o nome de 'liberdade' (FICHTE, 2005, p. 52-53)

Assim, Fichte extrai desta dedução o postulado, implicado no pensamento do ser racional como tal, destes seres como devendo determinar-se conscientemente a si mesmos, apenas e através de conceitos e, de fato, do conceito da "auto-atividade absoluta". Daí, vangloria-se Fichte, ter sido afastada toda a obscuridade, misticismo e "entusiasmo", e ter sido tornado compreensivel o famoso "imperativo categórico" de Kant, ao que o jovem Schopenhauer contesta:

Pura presunção! O próprio fato de que haja algo incompreensível, que esta natureza deplorável do Entendimento e de seus conceitos seja limitada, condicionada e, ultimamente, falaciosa; este é certamente o valor de Kant. (SCHOPENHAUER, 1988, MR2, p. 401)

Vemos, assim, que o jovem Schopenhauer recusa o principal do empreendimento em que Fichte está empenhado, já que ele recusa, e isto já desde suas mais precoces anotações (SCHOPENHAUER, 1988, MR1, p. 46-7, 54-5; MR2, p. 276-7), toda a doutrina kantiana acerca da Razão Prática, doutrina esta que Fichte pretende implementar. Para o jovem Schopenhauer, a única função prática da Razão é a de fornecer máximas da sabedoria prática, ou da prudência, ao passo que a moralidade tem lugar num outro estado de consciência, diferente daquele da consciência empírica, estado outro este chamado por Schopenhau- 
er nesta época de "consciência melhor", que prescinde de qualquer fundamentação racional. Mas Fichte, neste seu Sistema da Ética, condena esta ideia de que a Razão pode ser apenas tecno-prática - para ele, a dignidade prática da Razão consiste em sua absolutez, sua não-determinabilidade por nada fora de si mesma, e sua determinação completa através de si mesma. Quem quer que não lhe reconheça estaabsolutez, adverte Fichte, será incapaz de compreender como a razão pode ser absolutamente prática, e sempre acreditará que ela, a razão, se limita a encontrar os meios para um fim que é dado fora dela mesma, dado pelas necessidades naturais ou por nossa escolha livre (freie Willkür), e sempre acreditará que as condições para o cumprimento da lei precisam ser conhecidos antes dessa lei ser reconhecida (FICHTE, 2005, p. 59). Daí, conclui Fichte, "Ou toda a filosofia precisa ser abandonada, ou a absoluta autonomia da razão precisa ser concedida", pois toda afirmação de sua heteronomia é contrária à Razão e em conflito com ela (FICHTE, 2005, p. 60). É claro que, mesmo quando jovem, Schopenhauer recusava isto, a autonomia da Razão, que Fichte colocava como condição da filosofia. Quando acompanhamos esta, digamos, implementação da razão prática kantiana promovida por Fichte em seu Sistema daÉtica, vemos o quanto Schopenhauer, mesmo quando jovem, já dela radicalmente se afastava - ao "imperativo categórico" kantiano, que ordena a submissão à lei independentemente de qualquer inclinação, independentemente das condições (recompensa ou punição) desta submissão, Schopenhauer sempre oporá seu famoso: "E o que acontece, se eu não me submeter à lei?”. A Razão, com suas leis e conceitos, sempre tem, para Schopenhauer, apenas o caráter tecno-prático que lhe é recusado, acima, por Fichte, ela apenas fornece os meios para um fim que lhe é dado a partir de fora dela mesma, o que significa que, para Schopenhauer, a Razão não tem uma finalidade própria; e a "vontade" de Fichte e Kant, que sempre está vinculada àquela auto-determinação através de conceitos, àquela autonomia da Razão, permanece, sob este aspecto, radicalmente diferente do conceito schopenhaueriano de Vontade.

\section{3) A liberdade como negação da Vontade.}

Mas, apesar desta rejeição quase completa das pretensões de Fichte, encontramos, no entanto, no Sistema da Ética, alguns desenvolvimentos que, parece-nos, justificam a última e importantíssima anotação nele feita pelo jovem Schopenhauer. Quando aquele impulso, causalmente produzido por condições antecedentes na série natural, cai sob a tutela do intelecto e do conceito, aquela série natural é interrompida, pois, diz Fichte, trata-se agora de algo que en faço, e, embora neste fazer eu empregue uma força que provém da natureza, já não se trata de uma força natural, mas sim de uma força minha. Fichte chama este tipo de agir consciente, desta consciência que o Eu tem de ser, independentemente de qualquer fator externo, o autor de sua ação, de "liberdade formal". Mesmo que, neste agir, este Eu seguisse e satisfizesse, sem exceção, apenas ao impulso natural, se tal agir fosse acompanhado daquela consciência, então ele seria formalmente livre (FICHTE, 2005, p.128-129). Por "liberdade material", por outro lado, Fichte entende a capacidade de "determinar-se sem qualquer referência ao impulso natural, e mesmo de maneira contrária a ele", o que implica numa nova série de ações, diferentes daquelas que seriam produzidas na série natural (FICHTE, 2005, p.132-133). Este último tipo de liberdade, a liberdade material, supõe que, contrastado ao impulso natural, entre em cena um novo impulso, um impulso que se "desvia do impulso natural, que não obedece ao impulso natural, resiste e se opõe a ele". Fichte, assim, contrapõe, ao impulso natural, o impulso "puro"; sobretudo, diz Fichte, o impulso puro é um impulso mais "alto", é um impulso que me eleva acima da natureza, e exige que o Eu se determine de forma completamente independente do ímpeto da natureza. Assim, diz Fichte, "O impulso puro não busca prazer (Genuss) de nenhum tipo, ao contrário, ele despreza todo prazer. Ele torna o prazer algo detestável como tal.” (FICHTE, 2005, p. 135). Enquanto o impulso natural se dirige ao prazer, o impulso puro procura a independência do agente em relação a todos 
impulsos naturais, e o que ele exige é que, aquilo que é solicitado pelo impulso natural, simplesmente não lhe seja dado:

Isto significa que nada decorre do impulso puro, a não ser alguma abstenção (Unterlassung); ele não poderia produzir nenhuma ação positiva para além da ação íntima de auto-determinação. Se todos os autores que trataram da ética de maneira formal houvessem procedido consistentemente, então eles não poderiam ter chegado a nada, a não ser a uma contínua auto-negação(Selbstverläugnung), a uma última aniquilação e desaparecimento - como aqueles místicos que dizem que deveríamos nos perder em Deus." (FICHTE, 2005, p. 140/183)

Veremos que estaauto-negação, exigida pelo impulso puro de Fichte, está muito próxima da autonegação da Vontade, tal como formulada por Schopenhauer. Mas, continua Fichte, a liberdade precisa ser posta como algo positivo, e não como mera abstenção, precisa ser uma ação resultante de um querer efetivo que, incidindo sobre objetos sensíveis, emprega sobre estes uma força igualmente sensível, força esta que, embora posta sob o controle intelectual do Eu, foi tomada de empréstimo ao impulso natural, e, como este "só empresta quando recebe algo em troca", a ação precisa ser adequada, também, a este impulso natural. Daí que, embora o Eu, nesta situação, encontre-se impelido a fazer algo cujo fundamento encontrase apenas nele mesmo, ele, de fato, não pode fazer nada que não seja o exigido por algum impulso natural, ele não pode querer nada, a não ser aquilo que a natureza, se ela possuísse vontade, quereria (FICHTE, 2005, p. 141). E, no entanto, o impulso puro precisa ter alguma causalidade, efetividade e satisfação. Tal contradição, diz Fichte, só pode ser resolvida mediante a consideração de que, no caso de uma única e mesma ação, ela seja simultaneamente adequada ao impulso natural e ao impulso puro. Isto, diz Fichte, só pode ser compreendido assim:

(...) a intenção (Absicht), o conceito (Begriff) que está envolvido na ação, procura a completa liberação em relação à natureza. Mas não é em consequência deste conceito livremente forjado por nós que a ação seja e permaneça adequada ao impulso natural; ao contrário, isto é consequência de nossa limitação (...). O impulso puro procura a independência absoluta; uma ação é adequada ao impulso puro quando ela é voltada à independência absoluta, i.e., quando ela está numa série de ações em cuja continuação o Eu se tornaria independente (...), entretanto, o Eu nunca pode chegar a ser completamente independente (...). Consequentemente, o fim final (Endzweck) do ser racional necessariamente está na infinidade (...).” (FICHTE, 2005, p.142/186).

É preciso, diz Fichte, que haja tal série, em cuja continuação o Eu, embora tenha, a cada momento, diante dos olhos uma finalidade sempre determinada, finalidade esta em direção a qual o Eu, impelido por algum impulso natural, pode se aproximar cada vez mais, esta finalidade, uma vez atingida, dá lugar a uma finalidade mais expandida, e assim, indefinidamente, de modo que este Eu pode, paulatinamente, se aproximar da, embora nunca possa chegar a, aquela finalidade final do impulso puro. Em cada uma das determinações desta série, os dois impulsos, o puro e o natural, precisam coincidir ao menos parcialmente, e então, como um impulso "ético", obtém do impulso natural a matéria (o impulso ético se dirige, ao menos em parte, para a mesma ação para a qual se dirige o impulso natural), e obtém do impulso puro a forma:

Tal como o impulso puro, ele (o impulso ético) é absoluto; ele exige algo, pura e simplesmente, e não em função de algo outro. Ele absolutamente não se dirige a nenhum prazer, seja de que tipo for. A finalidade última de tudo o que é exigido pelo impulso ético é a independência completa. Mas qual é, por sua vez, a finalidade desta independência completa? Será talvez algum prazer, ou algo similar? Absolutamente não. A independência absoluta é seu próprio fim (...). O contentamento íntimo que se sente 
no dirigir-se a este objetivo é algo contingente. (FICHTE, 2005, p. 144-145).

Assim, diz Fichte, "a rigortodo conceito-de-fim possivel dirige-se à satisfação de um impulso natural", pois todo querer efetivo é um querer empírico, e uma "vontade pura", ou aquele impulso puro, é apenas uma ideía, é algo que não se apresenta na consciência, é algo pertinente ao domínio inteligível, e que é meramente pensado como fundamento explicativo daquilo que é empírico (FICHTE, 2005, p. 141). Vemos, aqui, aquela mesma referência ao caráter meramente acessório da teleologia ou do conceito-de-fim relativamente ao impulso que, anteriormente, e em conexão com o curso Sobre os fatos da consciência, Fichte apresentou diante do jovem Schopenhauer. Como se trata aqui de um impulso já posto sob a tutela do intelecto e dos conceitos, temos que, em cada querer efetivo, um conceito-de-fim é forjado pelo intelecto, de modo a atender e fazer com que um impulso natural seja satisfeito, pois esta é uma condição necessária de toda ação. E isto, mesmo e também da ação moral! O impulso ético é satisfeito apenas na medida em que o conceito-de-fim, que acaba de ser realizado, e cuja realização satisfez ao impulso natural, é posto como um mero elo de uma série cuja continuação indefinida aponta para, mas nunca chega à, finalidade final exigida pelo impulso puro eternamente insatisfeito. É claro, porém, que, para Fichte, e conforme enfatizamos no início, mesmo o impulso puro possui uma finalidade, de modo que, para ele, o impulso da vontade nunca perde sua conexão para com os conceitos do intelecto e da Razão. Toda esta discussão, promovida pelo Sistema da Ética, sobre o impulso da vontade já parte do pressuposto de que tal impulso esteja "sob a tutela" dos conceitos do intelecto ou da Razão, o que faz com que a ideia de uma vontade não-conceitual, ou de uma vontade desprovida de conceito-de-fim, seja, para Fichte, uma ideia impossível. Porém, quando consideramos que esta finalidade última (Endzweck) do impulso puro, e consequentemente do impulso ético também, é, por assim dizer, vaz̧ia, ou é algo negativo, como a abstenção, a auto-negação, de que falava Fichte acima, então parecemos nos aproximar mais ainda daquilo que será proposto por Schopenhauer. É assim que Fichte define o exíguo "conteúdo" desta finalidade última do impulso puro dos seres racionais:

Em resumo, a finalidade do impulso, quando apreendida em sua totalidade, é a absoluta autosuficiência do Eu como tal (...). Eu sou suposto ser um Eu auto-suficiente; esta é a minha finalidade última. Eu sou suposto usar as coisas de um modo que vá aumentar estaauto-suficiência; esta é a finalidade última destas coisas." (FICHTE, 2005, p. 201)

Enfim, podemos ver como o caráter ético do impulso consiste neste modo em que, instalados na perspectiva do impulso puro, e de sua finalidade negativa de auto-suficiência e auto-determinação em função da auto-suficiência e auto-determinação mesmas, as ações efetivas, que realizam os indefinidamente reiteráveis conceitos-de-fim que atendem aos impulsos naturais, são como que esvaziadas, relativizadas, e postas como meros meios para aquela finalidade negativa e última de auto-suficiência. É assim que Fichte pretende desenvolver a doutrina kantiana a respeito do caráter exclusivamente formal do "imperativo categórico".

Parece-nos que é em relação a estas considerações de Fichte a respeito do impulso puro, e de suas relações para com o impulso natural, que Schopenhauer faz uma extensa anotação, absolutamente fundamental para o desenvolvimento de seu pensamento filosófico. Apesar de localizada na seção 14, parte III, do Sistema da Ética, intitulada "Sobre a vontade em particular", a respeito da qual o jovem Schopenhauer observa que nela "tem muito sobre a vontade que vale a pena ler", o teor todo das considerações que ele faz diz respeito, inequivocamente, àquilo que Fichte, há pouco, dizia sobre o impulso puro, e sobre o modo como, em relação a este, os indefinidamente reiteráveis conceitos-de-fim, exigidos pelos impulsos natu- 
rais, são, conforme dissemos, vestimentas provisórias. Segundo diz Schopenhauer nesta anotação, " $A$ liberdade do querer poderia ser chamada de liberdade do não-querer (FreiheitdesNichtwollens)". As ações do arbítrio, resultantes de uma escolha refletida entre objetos do desejo, e que são possíveis através do desprender-se do tempo presente (o que nos distingue dos animais), compõem aquilo que propriamente deve ser entendido como a "Razão Prática", e isto, acrescenta o jovem Schopenhauer, "não importando o quanto os kantianos vão protestar”. Mas, continua ele:

A liberdade da vontade é a capacidade de destruir o todo da vontade própria, e sua lei suprema é: 'Não quererás nada' (Du sollstnichtwollen) (...). Agora, embora neste caso todo o querer tenha terminado, minha ação entretanto aparece como a consequência de um querer, mas ela só aparece assim. Eu ajo como se o objeto (da ação) me fosse dado por um conceito-de-fim, pois no momento de agir eu chego mesmo a forjá-lo para tal, pois esta é uma condição de toda ação (...). Entretanto, eu não ajo como eu quero, mas sim como eu devo, (ajo) como o instrumento de algo inexprimível, de uma lei eterna. Embora em tal ação puramente moral eu faça, pro forma, do objeto meu conceito-de-fim, ainda, de fato, este não é tal, não se trata do conceito-de-fim ser realizado, um acidente pode suspender o efeito todo da ação moral, isto não importa - por isso Kant chama a lei moral de lei formal (...)." (SCHOPENHAUER, 1988, MR2, p. 402-403/(1864), HN, p. 182)

Daí, finaliza Schopenhauer, que o homem virtuoso age como se ele quisesse (algo), mas ele de fato já não quer (nada), e este homem pode ser comparado a um falcão domado, que age como se estivesse em busca de uma presa, embora ele já não seja predador, e esteja caçando apenas para seu dono.

Comentando esta mesma passagem de Schopenhauer e de Fichte, Zöller, no artigo já mencionado aqui, procura mostrar que Schopenhauer, radicalizando a distinção fichteana entre liberdade material, entendida como "poder de escolha", e liberdade formal, entendida como a capacidade de "desprender-se do momento presente", separa a liberdade própria ao poder de escolha, ao qual será confinada a "Razão", da liberdade da Vontade, separa a liberdade de escolha da liberdade relativamente à (qualquer) escolha ("freedomofchoice" x "freedomfromchoice"). Na medida em que, continua Zöller, Schopenhauer confina a razão prática ao poder de escolha (que inclui, tanto a escolha entre moralidade e imoralidade, como a escolha entre motivos moralmente irrelevantes) e como a liberdade da vontade já não é um poder de escolha, a liberdade da vontade já não pode mais ser concebida, como a concebia Kant, como a sua capacidade de auto-legislação racional, ou autonomia, e se apresenta agora como a capacidade de "destruir o todo da vontade própria". Mas, como Schopenhauer ainda não pensa numa vontade supra-individual, a instância a ser encarregada da ação moral, uma vez destruída a vontade individual, será, diz Zöller, um princípio supra-sensível, uma lei moral "objetiva", que se aproxima muito da "consciência do Dever puro" de Fichte e de Kant. Deste modo, diz Zöller:

a "ética de Fichte não fornece apenas uma ocasião externa para a descoberta de Schopenhauer do princípio quietista da moralidade (...) a ética do não-querer de Schopenhauer surge do espírito da filosofia moral fichte-kantiana (ZÖLLER, 2012, p.378-379).

Assim, conclui Zöller, se para Kant a ação moral consiste no acordo do querer (a vontade "pura" com o dever moral, Fichte dissocia este dever, ou norma absoluta, da vontade, e considera o dever como um princípio supra-individual de ação, que emprega os indivíduos como meros veículos. Foi assim, diz Zöller, que Schopenhauer encontrou os meios para superar o "conto de fadas" de Fichte em Fichte mesmo (ZÖLLER, 2012, p.380). 
Mas, a respeito deste comentário de Zöller, gostaríamos de formular as seguintes considerações: em primeiro lugar, o fato de Schopenhauer restringir a Razão prática, mesmo enfrentando os protestos dos "kantianos", à escolha segundo as regras da prudência, ou, conforme rejeitado acima por Fichte, ao caráter tecno-prático das ações, não parece decorrer apenas desta leitura realizada por ele do Sistema da Eticidade de Fichte em 1812 - de fato, muitos outros manuscritos do jovem Schopenhauer, anteriores a esta data, e não conectados ao nome de Fichte, já recusava a atribuição, por parte de Kant, de qualquer função ou valor moral da Razão (SCHOPENHAUER, 1988, MR1, p. 46-7, 54-5). Em segundo lugar, a distinção que Zöller atribui a Fichte entre as liberdades formal e material não corresponde àquela que, como vimos há pouco, parece ter sido a feita por Fichte - Zöller vê a liberdade da vontade, enquanto contrastada à liberdade de escolha, como conectada à liberdade "formal", mas, como vimos, é apenas com a liberdade "material" que entra em cena aquele impulso puro, que se restringe a dizer "Não!" à satisfação dos impulsos naturais. Vimos que, o que este impulso puro quer, o que ele tem por finalidade última (Endzweck), é algo inteiramente negativo, e, como dizia Fichte, o que ele quer é a "abstenção", ou a "autoaniquilação" e "auto-negação"(FICHTE, 2005, p.140/183) do indivíduo, e é justamente esta finalidade última de auto-negação aquilo que poderíamos assinalar como a antecessora fichteana da liberdade do nãoquerer de Schopenhauer. E, em terceiro lugar, devemos considerar que Zöller, ao falar daquele poder de escolha ao qual se restringe agora a Razão prática, afirma que ele pode incidir, tanto sobre a escolha entre motivos morais e motivos não-morais, como sobre, no interior destes últimos, entre motivos moralmente irrelevantes, mas, parece-nos, a novidade da ideia avançada aqui pelo jovem Schopenhauer é que não há motivos morais - a moralidade agora consiste apenas em que, apesar de aparentar ser iniciada e guiada por um conceito-de-fim, a ação moral não procura realmente alcançar nenhum fim, nela não se trata de realizar nenhum conceito-de-fim. E, por último, devemos considerar que o caráter meramente "formal" e vazio do imperativo categórico de Kant, assim como o caráter negativo e inalcançável da finalidade última do impulso puro de Fichte, se bem que apontam na direção a ser seguida por Schopenhauer, ainda são, ambos, conectados necessariamente por Kant e Fichte à Razão, e, em particular, aos conceitos-de-fim que só são possíveis pela Razão.

Com efeito, é em conexão com esta discussão de Fichte, acima, discussão que aparece também, e como vimos anteriormente, no curso Sobre os fatos da Consciência, sobre as relações entre o impulso da vontade e os conceitos-de-fim, que se encontra o principal da contribuição de Fichte ao pensamento filosófico de Schopenhauer - pois em ambas as ocasiões Fichte coloca, e procura resolver, o problema da conciliação entre, de um lado, a eternidade, absolutez, e infinidade do impulso e, de outro lado, a sua satisfação através de um conceito-de-fim numa ação determinada. Utilizando as distinções feitas, acima, no Sistema da Eticidade, podemos dizer que, segundo Fichte, o impulso puro, para se manifestar, precisa utilizar o, por assim dizer, "pretexto" de um conceito-de-fim que é adequado, não a ele, mas sim a um impulso natural, e a ação daí decorrente, quando se deixa de lado o impulso natural já satisfeito, ou não, por ela, e quando posta numa série cuja continuação indefinidamente prolongável aponta para, sem nunca chegar a, finalidade final do impulso puro, satisfaz a um impulso "ético", que, por assim dizer, se despreende e considera como "vazios" cada um dos conceitos-de-fim já realizados. Assim, tanto em Fichte, como no jovem Schopenhauer, é como se a moralidade das ações dissesse respeito, não ao objeto ou objetivo da ação, não ao conceito-de-fim por ela satisfeito ou não (isso, diz. Schopenhauer acima, não importa!), mas sim dissesse respeito a este aspecto "formal", a esta perspectiva do impulso "puro" que se despreende, que relativiza e, por assim dizer, esvazia cada uma das finalidades, realizadas ou não, da ação. Parece ser este caráter de vestimenta necessáriamas provisória dos conceitos-de-fim relativamente ao impulso da vontade o que está sendo tematizado pelo jovem Schopenhauer na passagem acima, e é exata- 
mente isto o que deveríamos esperar do prolongamento das reflexões de Fichte, acima, a respeito do mesmo ponto.

\section{Referências}

CARTWRIGHT, D. (2010) Schopenhauer: a biography. Cambridge: Cambridge University Press.

FICHTE, J.G. (2005) The System of Ethics. Breazeale, D. e Zöller, G. (ed). Cambridge: Cambridge University Press/(1798) Das System der Sittenlehre. Jena und Leipzig:C.E.Gabler (http://books.google.com)

KANT, I. (1974) Kritik der reinen Vernunft. Frankfurt:Suhrkamp.

RAPPAPORT, S. (1889) Spinoza und Schopenhauer. Halle-Wittenberg: Halle Als (https://epdf.tips/spinoza-und-schopenhauer.htm)

SCHOPENHAUER, A. (1813) Über die vierfache Wurzel des Satz vom zureichenden Grunde. Rudolstadt:Bayerische Staats Bibliotek - Müncher Digitalisierungs Zentrum.

SCHOPENHAUER, A. (1988) Manuscript Remains. Vol. I "Early Manuscript” (MR1) e Vol. II "Critical Debates" (MR2). Hübscher, A.(ed). Oxford: Berg Publischers Ltda/Aus Arthur Schopenhauer's handschriften Nachlass (HN). Frauenstädt, J.(ed). Leipzig: Brockhaus (http://books.google.com)

SCHOPENHAUER, A. (1996) Die Welt als Wille und Vorstellung. Vols. I e II. Frankfurt: Insel Verlag/ (1969) The World as Will and Representation. Vols. I e II. Payne, E.F.J.(trad). New York: Dover Publications Inc.

SCHOPENHAUER, A. (2010) The Two Fundamental Problems of Ethics. Cartwright, D. e Erdemann, E.(trad). Oxford: Oxford University Press.

SEGALLA, M. e DE CIAN, N. (2002). "What is will?" In:Schopenhauer-jahrbuch.

ZÖLLER, G. (2009). "Schopenhauer on the Self". In: Janaway, C.(ed) The Cambridge Companion to Schopenhauer. Cambridge: Cambridge University Press.

ZÖLLER, G. (2012) “Schopenhauer's Fairy Tale about Fichte”. In: Vandenabeele, B.(ed). A Companion to Schopenhauer. UK:Wiley-Blackwell. 